\title{
Phytochemical Screening, Antioxidant Effect and Down Regulation of TGF- $\beta$ Induced by Ophiocoma erinaceus Brittle Star Crude Extract
}

\author{
Javad Baharara," and Elaheh Amini ${ }^{2}$ \\ ${ }_{1}^{1}$ Research Center for Animal Development Applied Biology, Department of Biology, Mashhad Branch, Islamic Azad University, Mashhad, IR Iran \\ ${ }^{2}$ Department of Animal Biology, Faculty of Biological Sciences, Kharazmi University, Tehran, IR Iran \\ *Corresponding author: Javad Baharara, Research Center for Animal Development Applied Biology, Department of Biology, Mashhad Branch, Islamic Azad University, Mashhad, IR \\ Iran. E-mail: baharara@yahoo.com
}

Received 2014 August 25; Accepted 2014 September 24.

\begin{abstract}
Background: Recent investigations get focused on characterization and isolation of natural compounds with pharmaceutical applications from terrestrial and aquatic ecosystem. Marine invertebrate natural products have been proposed due to various structural diversity. Ophiocoma eraniceus (O. erinaceus) is a brittle star species belonging to Echinodermata that distributed in Qeshm island in the Persian Gulf. Recent scientist researches have concentrated on discovery of natural resources with pharmacological and biomedical potential.

Objectives: This experiment aimed to discover phytochemical analysis and in vitro antioxidant and anti-inflammatory properties of $O$. erinaceus methanolic extract.

Materials and Methods: In this experimental study, the phytochemical analysis were conducted to determine saponin, phenolic and flavonoid content of brittle star and the free radical scavenging activity with two in vitro assays. In addition, the effect of methanolic brittle star extract on TGF- $\beta$ expression were analysed by RT-PCR.

Results: The phytochemical studies established the presence of saponins, phenol, and flavonoids compounds in the brittle star extract and the antioxidant results from DPPH (1,1-diphenyl-2-picrylhydrazyl), ABTS (azino-bis-3-ethylbenzothiazoline-6-sulfonic acid) revealed that $O$. erinaceus displayed antioxidant activity as dose dependent manner. On the other hand, $O$. erinaceus extract inhibited TGF- $\beta$ expression which indicate anti-inflammatory properties of 0 . erinaceus.

Conclusions: In conclusion, these results clearly exhibited that the 0 . erinaceus methanolic extract possess valuable constituents that may correspond as a natural antioxidant and anti-inflammatory agent useful in biomedicine.
\end{abstract}

Keywords: Echinodermata, Phytochemical, Antioxidant, Anti-Inflammatory

\section{Background}

Brittle stars are the large clade in Ophiuroidea with body outline (radial symmetry) related to starfish that possess 5 flexible arms for locomotion along with central disk containing viscera [1]. Most valuable properties of Ophiuroidea is ability of prominently repair lost arm segments [2]. Bioluminescence is other characteristic which brittle star apply to escape from predators with rare benefit for human health and moderately popular in fish keeping [3]. Ophiocoma erinaceus ( $O$. eraniceus) is one Persian Gulf brittle star that commonly inhabit in the rocky coast of Qeshm island [4]. Now, there are a few evidences on the basis of presence biological compounds such as terpenes, sterols, phenyl propanoids with anti-cancer and anti-bacterial effect in brittle star but their importance have not been reported in human health to date. Therefore screening plans to explore brittle star metabolites are inevitable. The diversity of metabolites in natural ecosystem increase pharmacological potential hence the performance of pharmacological assays related to brittle star relieve to identify their influences on correlated disease [5]. The human body expose with free radical by products that if not eradicate result to harmful oxidative stress effects and health complications. Constant oxidative stress by reactive oxygen species is associated with disorder development and many other health issues such as inflammatory disease [6]. Free radicals include superoxide, hydroxyl, hydrogen peroxide and nitric oxide eliminate via antioxidant enzymes like superoxide dismutase and catalase and natural antioxidants such as phenolic compounds and flavonoids that commonly exist in fruit and vegetables and herbs [7]. A number of assays have been proposed for assessment antioxidant potential of natural compounds to exclude oxidative stress deleterious effects so; extensive researches have been conducted to overwhelm oxidative stress. DPPH 
(1, 1-diphenyl-2-picrylhydrazyl) is relatively stable free radical with deep purple color that is reduced in the presence of potent antioxidant. Similarity, ABTS (azino-bis-3-ethylbenzothiazoline-6-sulfonic acid) assay is a decolorization technique along with generation of ABTS blue/green color via the reaction with potassium persulfate [8]. There is an increasing demand for detecting natural antioxidants that reduces collateral effects and provides health benefits. Numerous studies paid attention to the pharmacological and biological properties of terrestrial natural products [9]. Despite the existence of various plant antioxidants, marine echinoderms antioxidants have been reported scarcely suggesting requirement for development of novel natural antioxidant [10]. The literature research indicated no investigation about anti-oxidant potential of $O$. erinaceus crude extract as one of most species of brittle stars in Persian Gulf.

\section{Objectives}

Therefore, our study conducted to detect phytochemical constituents, antioxidant activity and anti-inflammatory effect of 0 . erinaceus crude extract.

\section{Materials and Methods}

\subsection{Chemicals}

DPPH, Quercetin and ABTS purchased from Sigma, USA. Gallic acid, Folin Ciocalteu reagent and methanol purchased from Merck, Germany. The RNA isolation kit purchased from Roshe, Germany. The C-DNA synthesis kit and RT-PCR kit purchased from Pars Tous, Iran. Specimens of the brittle star (O. erinaceus) collected from the rocky intertidal flats of the Persian Gulf waters.

\subsection{Brittle Star Methanolic Extraction}

In this experimental study, morphometric estimation of $O$. erinaceus performed at research center applied biology of Mashhad Islamic Azad university. Then, specimens of brittle stars washed and stored at $-80^{\circ} \mathrm{C}$. For preparing extract, brittle star samples (about $20 \mathrm{~g}$ ) dried, minced and mixed with $200 \mathrm{~mL}$ methanol. Then, the extract constantly stirred (72 hours) at room temperature, filtered through an $11 \mu \mathrm{m}$ Whatman filter and concentrated under vacuum evaporator and stored in $-20^{\circ} \mathrm{C}$.

Measurement of total phenolic content: In this experimental study, the total phenolic content of the $O$. erinaceus extracts was calculated with the Folin-Ciocalteu reagent. To perform this experiment, $100 \mu \mathrm{L}$ of methanolic brittle star extract or gallic acid as standard added to $250 \mu \mathrm{L}$ of Folin Ciocalteu reagent and $1.25 \mathrm{~mL}$ of $20 \%$ sodium carbonate. To accomplish this reaction, mixtures kept in dark for 40 minutes. Finally, the absorbance was measured at $725 \mathrm{~nm}$.

\subsection{Measurement of Total Flavonoids Content}

Total flavonoid content of $O$. erinaceus was measured on the basis of flavonoid-aluminium complex formation using quercetin as a standard. The extract or quercetin (1 $\mathrm{mL}$ ) was added to $1 \mathrm{~mL}$ methanolic solution of $\mathrm{AlCl}_{3} 2 \%$. After further 5 minutes incubation, the absorbance of reaction mixture was measured at $430 \mathrm{~nm}$.

\subsection{Measurement of Total Saponin}

To determine the presence of saponin in the brittle star extract froth test was performed. $1 \mathrm{~mL}$ of brittle star extract mixed with $20 \mathrm{~mL}$ distilled water in test tube and shacked vigorously. Foam layer formation was considered indicator of saponin existence.

\subsection{In Vitro Antioxidant Assays}

\subsubsection{DPPH Free Radical Scavenging Activity}

The antioxidant activity of brittle star extract was evaluated by scavenging of free-radical DPPH as compared with butylated hydroxy anisole (BHA) as a standard compound. Briefly, the different concentrations of brittle star extract $(100-2000 \mu \mathrm{g} / \mathrm{mL})$ were prepared in methanol and $0.2 \mathrm{~mL}$ mixed with $0.2 \mathrm{~mL}$ of $1 \mathrm{mM}$ DPPH solution in methanol. Then, absorbance was measured at $517 \mathrm{~nm}$ after 30 minutes incubation in dark with a micro plate reader and the bleaching activity was calculated using the following formula:

$$
\text { DPPH Radical Scavenging }(\%)=\left(\frac{\text { Control OD }- \text { Sample OD }}{\text { Control OD }}\right) \times 100
$$

\subsubsection{ABTS Radical Cation Decolorization Activity}

ABTS was dissolved by reacting $7 \mathrm{mM}$ ABTS stock solution in water with $2.45 \mathrm{mM}$ potassium persulfate and was stored at room temperature for 12 - 16 hours before utilization. The ABTS+ solution diluted with PBS to reach 0.80 \pm 0.03 absorbance at $734 \mathrm{~nm}$. The reaction mixture [ $(1 \mathrm{~mL}$ of standard (ascorbic acid) or different concentrations of brittle star extract was mixed to $1 \mathrm{~mL}$ of the ABTS stock solution)] and incubated for 30 minutes at room temperature. Finally, the absorbance was measured at $734 \mathrm{~nm}$ and the radical scavenging activity of ABTS+ by samples was calculated as:

(2) ABTS Scavenging Effect\% $=\frac{\text { (Control Absorbance Sample Absorbance) }}{\text { (Control Absorbance) }} \times 100$

\subsection{Evaluation of Anti-Inflammatory Capacity}

\subsubsection{Cell Culture}

A2780cp cell line were grown in RPMI1640 cell culture medium containing 10\% fetal bovine serum (FBS) (Gibco, USA) and $1 \%$ antibiotic at $37^{\circ} \mathrm{C}$ in a $5 \% \mathrm{CO}_{2}$ incubator. Treatment was performed in the logarithmic phase of cell growth in $80 \%$ density. 
3.6.2. Total RNA Isolation and Reverse TranscriptionPolymerase Chain Reaction of TGF- $\beta$

The changes in the expression of TGF- $\beta$ mRNA was analyzed by RT-PCR. Total cellular RNAs of A2780cp treated cells and untreated cells were isolated by the high pure RNA Isolation kit (Roche, Germany). Two $\mu g$ RNA isolated was reverse transcribed to cDNA using easy cDNA synthesize (ParsTous, Iran) kit according to manufactures protocol. Briefly, cDNA synthesize was performed in the presence of random hexamer or oligo $\mathrm{dT}$, then incubated at $65^{\circ} \mathrm{C}$ for 5 minutes and followed by addition RT premix, incubation $25^{\circ} \mathrm{C}$ for 10 minutes, $50^{\circ} \mathrm{C}$ for 60 minutes and $70^{\circ} \mathrm{C}$ for 10 minutes and amplified according to manufacture protocol. Briefly, the produced cDNA $(2 \mu \mathrm{L})$ was added to $10 x$ buffer, $25 \mathrm{mM} \mathrm{MgCl}_{2}$, dNTP, Taq DNA polymerase, and the appropriate forward and reverse primers. Ultimately, RT-PCR was performed 1 cycle at $95^{\circ} \mathrm{C} / 4$ minute, 35 cycles as $94^{\circ} \mathrm{C} / 30$ seconds for denaturation, $57^{\circ} \mathrm{C} 30$ seconds for annealing, $72^{\circ} \mathrm{C} / 30$ seconds for extension and 1 cycles 5 minutes at $72^{\circ} \mathrm{C}$. The primers used were as follows: B2M Forward 5' TGGTGCTTGGCTCACTGACC 3', Reverse 5' TATGTTCGGCTTCCCATTCT $3^{\prime}$ was used as housekeeping gene. Forward primer and reverse primer TGF- $\beta$ was designed as $5^{\prime}$ GGGACTATCCACCTGCAAGA 3' and 5' CCTCCTTGGCGTAGTAGTCG 3', respectively.

\subsubsection{Following Amplification}

The PCR products were visualized by electrophoresis in a $2 \%$ agarose gel and visualized by green viewer staining.

\subsection{Statistical Analysis}

Our data are expressed as means \pm SD. Analysis of variance and significant differences were obtained by the SPSS-16 software, one-way ANOVA analysis. Values of P < 0.05 proposed significant.

\section{Results}

\subsection{Phytochemical Component Evaluation}

The foam test qualitatively demonstrated the presence of saponin in brittle star methanolic extract. The total phenolics and flavonoids compounds in brittle star extract were determined $4.51 \pm 0.025$ and $1.26 \pm 0.03$, respectively. Therefore, methanolic extract of brittle star possess total phenolic and flavonoids compounds that may correlated with antioxidant activity of brittle star extract.

\subsection{Radical Scavenging Activity of DPPH}

The comparison of DPPH scavenging effect of BHA with brittle star methanolic extract revealed brittle star extract exhibited dose dependent antioxidant activity against DPPH radical. BHA as standard displayed highly DPPH decolorization at all concentration tested. Figure
1 depicted the antioxidant efficacy of methanolic brittle star extract against DPPH free radical.

\subsection{ABTS Radical Scavenging Effect}

The ABTS free radical scavenging assay of brittle star extract exhibited methanolic brittle star extract possess antiradical activity dose dependently with IC50 value of as compared with Torolox as standard indicating the moderate potential of brittle star organic extract in decolorization of ABTS.

\subsection{Evaluation of TGF- $\beta$ mRNA Expression}

In the previous work on anti-proliferative effect of brittle star methanolic extract against HeLa cervical cancer cells IC50 value $=50 \mu \mathrm{g} / \mathrm{mL}$ determined. Analysis of the expression of TGF- $\beta$ by RT-PCR revealed a significant down regulation in the expression of TGF- $\beta$ in HeLa cells treated with brittle star extract at $50,100 \mu \mathrm{g} / \mathrm{mL}$ as compared with untreated cells demonstrating anti-inflammatory effect of brittle star extract in vitro.

Figure 1. DPPH Scavenging Activity of O. erinaceus Methanol Extract As Compared With BHA

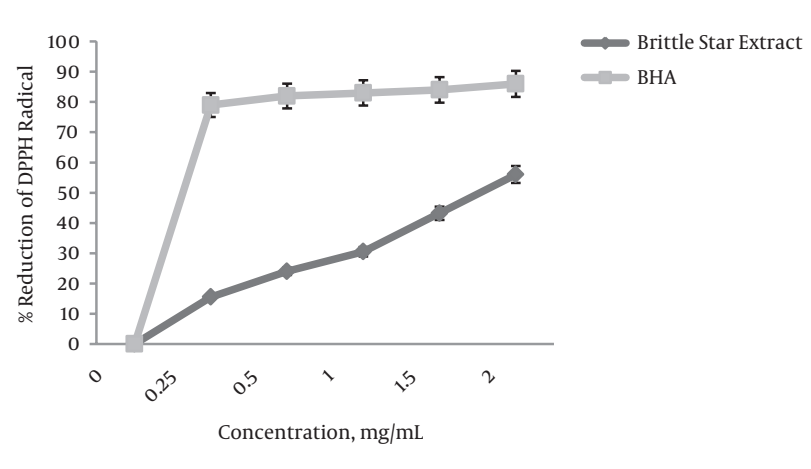

Each value is expressed as mean $\pm \operatorname{SD}(n=3)$.

Figure 2. ABTS Radical-Scavenging Activities of O. erinaceus Methanol Extract As Compared With Ascorbic Acid

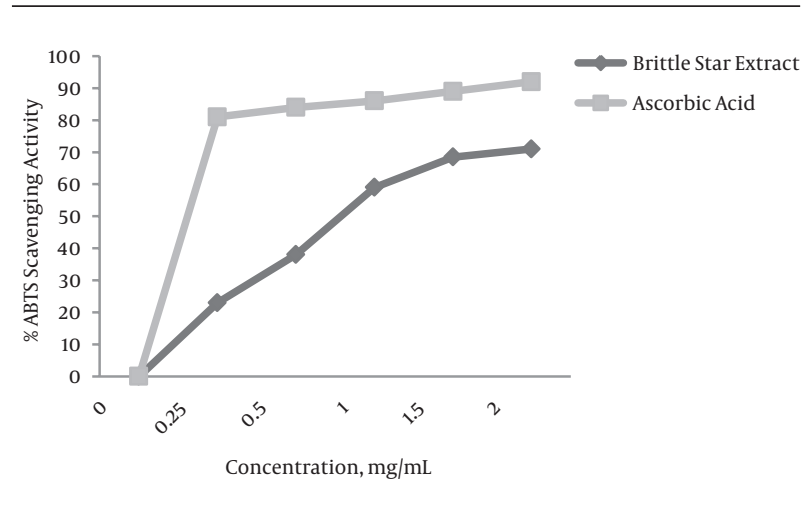

Each value is expressed as mean $\pm \operatorname{SD}(n=3)$. 


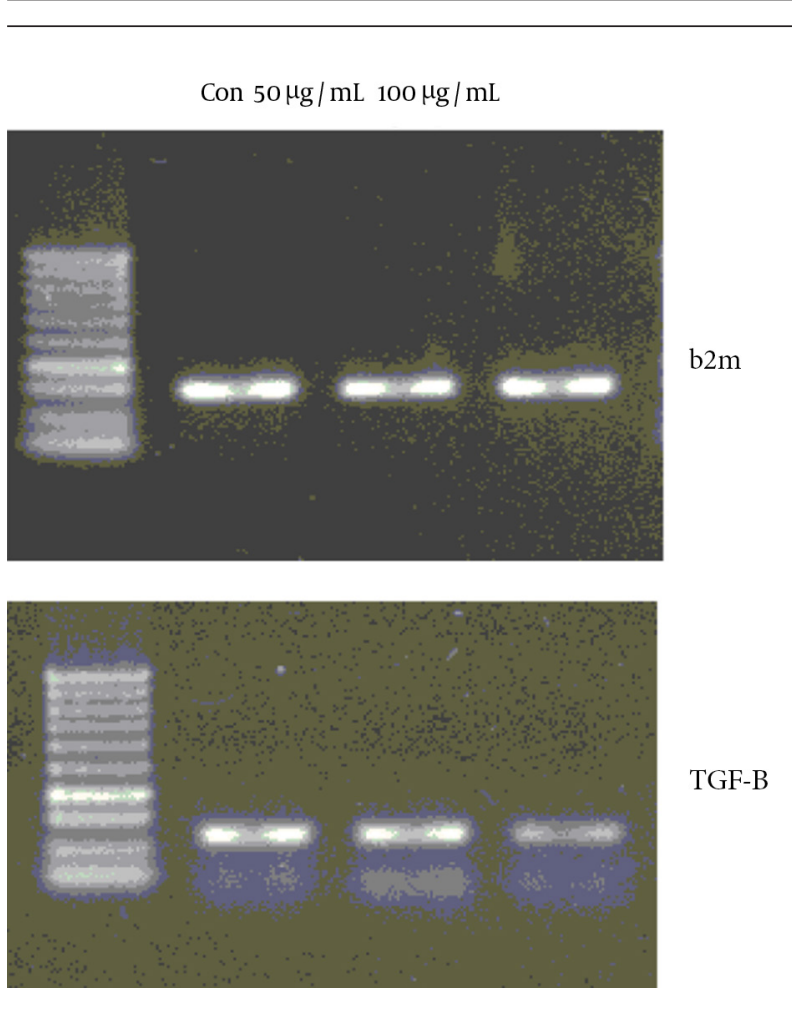

Figure 3. A2780co ovarian cancer cells were treated with brittle star extract and the mRNA expressions of TGF- $\beta$ and b2m were evaluated by RTPCR analysis that revealed anti-inflammatory effect of brittle star extract

\section{Discussion}

Our findings exhibited that methanol extract of brittle star possess valuable phytochemicals with considerable capacity to suppress free radical generation and scavenging activity of DPPH and ABTS which via down regulation of TGF- $\beta$ induce anti-inflammatory effect. The chemical compounds in natural resources can be considered bioactive metabolites possessing human health properties with anti-bacterial, anti-fungal, anti-oxidant, anti-cancer and anti-inflammatory biological effects [11]. Oxidative damage is proposed a complicated condition in the consequence of excessive generation of ROS that play essential role in the variety of degenerative disease such as diabetes, inflammatory disease and cancer, therefore, antioxidant regimen protects human body against oxidative stress injuries [12]. Natural substances such as vitamin C and vitamin $\mathrm{E}$ and phytochemicals provide powerful antioxidant activity, however, there is a growing interest for discovering novel natural antioxidants replacing to synthetic antioxidants with harmful side effects [13]. In this study, two assays have been carried out to determine the antioxidant potency of brittle star methanolic extract including DPPH and ABTS assay. The presence of phenolic, flavonoid and saponin compounds can be considered as one of antioxidant ingredients of brittle star organic extract that is in agreement with other investigations based on antioxidant activity of these ingredients in whole extracts. Adesanwo et al. investigated about the phytochemicals and antioxidant potential of roots of Tetracera potatoria. Their findings showed methanolic extract of Tetracera potatoria revealed more antioxidant activity in comparison with isolated compounds indicating synergism interactions of constituents in crude extract [14]. The research conducted by Padmanabhan et al. revealed the combination of alcoholic extract of leaves of Aloe vera, Bacopa monniera, Moringa oleifera and rhizome of Zingiber officinale showed better antioxidant activity against DPPH radical [15].

About antioxidant potential of marine organisms as immense resources of bioactive substances, Marxen et al. were assessed antiradical capacity of methanolic microalgae extracts and reported Isochrysis galbana, Phaeodactylum tricornutum, Porphyridium purpureum indicated DPPH scavenging activity [16]. Balboa et al. were evaluated antioxidant capability of brown algae crude extract and concluded that brown alga composed of highly bioactive metabolites such as polysaccharide, phenol, phlorotanin, protein, peptide, lipids and steroids that cannot be found in terrestrial organisms which confered more antioxidant ability compared with red and green algae [17]. There are a few reports related to antioxidant potential of marine echinoderm. In this respect, Althunibat et al. studied cytotoxic and antioxidant effects of three species of sea cucumber Holothuria scabra, Holothuria leucospilota and Stichopus chloronotus and demonstrated highest phenolic compound in water extract of $H$. leucospilota and lowest in organic extract of $H$. scabra. Aqueous extract of three species showed antioxidant activity and all organic extract elucidated anti-proliferative effects against A549 and C33A cancer cells in vitro [10].

Althunibat et al. were evaluated cytotoxic and antioxidant effect of two sea cucumber aqueous and organic extract from Holothuria edulis Lesson (Holothuriidae) and Stichopus horrens Selenka (Stichopodidae). Their results revealed that both extracts exhibited DPPH radical decolorization effect but the organic extract of Stichopus horrens indicated highest growth inhibitory effect which proposed them as promising natural antioxidants in biomedicine researches [18]. The previous researches documented the anti-cancer activity of natural products can be related to anti-inflammatory and antioxidant properties. Gautam et al. reported n-hexane and ethyl acetate extract of Dysophylla stellata can be consider valuable modality in inflammatory experiments because of suppression edema in mice resulted to down regulation of COX-1, COX-2 while only ethyl acetate extract indicated in vitro antioxidant properties [19].

Joseph et al. carried out antioxidative and anti-inflammatory assay on Ganoderma lucidum chloroform extract and indicated radical scavenging effects significantly and anti-inflammatory in vivo compared with diclofenac that establish positive relationship between antioxidant and anti-inflammatory activity [20]. However, anti-inflammatory response possess tremendous application in cancer prevention and treatment. Relationship of antioxidant, anti-inflammatory and anti-cancer properties of natural extracts were documented recently [21]. Suresh et al. evaluated 
anti-inflammatory and anti-tumor effects of Cuscuta reflexa in vitro and suggested this extract suppressed COX-2 and TGF- $\beta$ and had valuable anti-inflammatory activity that can be use in cancer therapy [22]. Tsai et al. offered wild Glossogyne tenuifolia extract indicated antioxidant, cytotoxic and inflammation modulatory effects of natural extracts that provided high bioactivity in biomedicine [23]. In this study, anti-inflammatory potential of brittle star methanolic extract were evaluated in vitro and indicated brittle star methanolic extract revealed dose dependent anti-inflammatory activity. Taken together, these reports accommodated with our findings indicating direct relation of antioxidant and anti-inflammatory effects of natural extracts. In this study we demonstrated that the chief constituents of brittle star methanolic extract are phenolic, flavonoids and saponin compounds that might be responsible for antioxidant and anti-inflammatory properties in vitro which proposed the therapeutic capacity of brittle star methanolic extract in prevention of oxidative damage related diseases.

\section{Acknowledgments}

The authors would like to thank respectful researchers at research center for animal development applied biology, Islamic Azad university of Mashhad who collaborated with doing this project (code number:366).

\section{Footnotes}

Authors' Contribution:All authors had equal role in design, work, statistical analysis and manuscript writing. Conflict of Interest:The authors declare no conflict of interest.

Funding/Support:Research center for animal development applied biology, Mashhad branch, Islamic Azad university.

\section{References}

1. Gondim AI, Alonso C, Dias TL, Manso CL, Christoffersen ML. A taxonomic guide to the brittle-stars (Echinodermata, Ophiuroidea) from the State of Paraiba continental shelf, Northeastern Brazil. Zookeys. 2013;(307):45-96. doi: 10.3897/zookeys.307.4673. [PubMed: 23794923]

2. Czarkwiani A, Dylus DV, Oliveri P. Expression of skeletogenic genes during arm regeneration in the brittle star Amphiura filiformis. Gene Expr Patterns. 2013;13(8):464-72. doi: 10.1016/j. gep.2013.09.002. [PubMed: 24051028]

3. Gage JD, Anderson RM, Tyler PA, Chapman R, Dolan E. Growth, reproduction and possible recruitment variability in the abyssal brittle star Ophiocten hastatum (Ophiuroidea: Echinodermata) in the NE Atlantic. Deep Sea Res, Part I. 2004;51(6):849-64. doi: 10.1016/j.dsr.2004.01.007.

4. Fatemi SMR, Jamili S, Valinassab T, Kuranlu N. Diversity of Ophiuroidea from Lengeh Portand Qeshm Island in the Persian Gulf. $J$ Fish Aqua Sci. 2010;5(1):42-8.

5. Wang WH, Lee CO, Shin S. Bioactive Metabolites from the brittle star Ophioplocus japonicus. Nat Prod Sci. 2004;10(6):253-61.

6. Bendary E, Francis RR, Ali HMG, Sarwat MI, El Hady S. Antioxidant and structure-activity relationships (SARs) of some phenolic and anilines compounds. Ann Agric Sci. 2013;58(2):173-81. doi: 10.1016/j.aoas.2013.07.002.

7. Lizcano LJ, Bakkali F, Begona Ruiz-Larrea M, Ignacio Ruiz-Sanz J. Antioxidant activity and polyphenol content of aqueous extracts from Colombian Amazonian plants with medicinal use. Food Chem. 2010;119(4):1566-70. doi:10.1016/j.foodchem.2009.09.043.

8. Thaipong K, Boonprakob U, Crosby K, Cisneros-Zevallos L, Hawkins Byrne D. Comparison of ABTS, DPPH, FRAP, and ORAC assays for estimating antioxidant activity from guava fruit extracts. J Food Compos Anal. 2006;19(6-7):669-75. doi: 10.1016/j. jfca.2006.01.003.

9. Celik SE, Ozyurek M, Guclu K, Apak R. Solvent effects on the antioxidant capacity of lipophilic and hydrophilic antioxidants measured by CUPRAC, ABTS/persulphate and FRAP methods. Talanta. 2010;81(4-5):1300-9. doi: 10.1016/j.talanta.2010.02.025. [PubMed: 20441899]

10. Althunibat OY, Hashim RB, Taher M, Daud JM, Ikeda MA, Zali BI. In vitro antioxidant and antiproliferative activities of three Malaysian sea cucumber species. Eur J Sci Res. 2009;37(3):376-87.

11. Liu X, Sun Z, Zhang M, Meng X, Xia X, Yuan W, et al. Antioxidant and antihyperlipidemic activities of polysaccharides from sea cucumber Apostichopus japonicus. Carbohydr Polym. 2012;90(4):1664-70. doi: 10.1016/j.carbpol.2012.07.047. [PubMed: 22944431]

12. Ponou BK, Teponno RB, Ricciutelli M, Quassinti L, Bramucci M, Lupidi G, et al. Dimeric antioxidant and cytotoxic triterpenoid saponins from Terminalia ivorensis A. Chev. Phytochemistry. 2010;71(17-18):2108-15. doi: 10.1016/j.phytochem.2010.08.020. [PubMed: 20850160]

13. Kapoor R, Srivastava S, Kakkar P. Bacopa monnieri modulates antioxidant responses in brain and kidney of diabetic rats. Environ Toxicol Pharmacol. 2009;27(1):62-9. doi: 10.1016/j. etap.2008.08.007. [PubMed: 21783922]

14. Adesanwo JK, Makinde OO, Obafemi CA. Phytochemical analysis and antioxidant activity of methanol extract and betulinic acid isolated from the roots of Tetracera potatoria. J Pharm Res. 2013;6(9):903-7. doi:10.1016/j.jopr.2013.09.003.

15. Padmanabhan P, Jangle SN. Evaluation of DPPH radical scavenging activity and reducing power of four selected medicinal plants and their combinations. Int J Pharm Sci Drug Res. 2012;4(2):143-6.

16. Marxen K, Vanselow KH, Lippemeier S, Hintze R, Ruser A, Hansen UP. Determination of DPPH radical oxidation caused by methanolic extracts of some microalgal species by linear regression analysis of spectrophotometric measurements. Sensors. 2007;7(10):2080-95.

17. Balboa EM, Conde E, Moure A, Falque E, Dominguez H. In vitro antioxidant properties of crude extracts and compounds from brown algae. Food Chem. 2013;138(2-3):1764-85. doi:10.1016/j.foodchem.2012.11.026. [PubMed: 23411309]

18. Althunibat OY, Ridzwan BH, Taher M, Daud JM, Jauhari Arief Ichwan S, Qaralleh H. Antioxidant and cytotoxic properties of two sea cucumbers, Holothuria edulis lesson and Stichopus horrens Selenka. Acta Biol Hung. 2013;64(1):10-20. doi: 10.1556| ABiol.64.2013.1.2. [PubMed:23567827]

19. Gautam R, Srivastava A, Jachak SM, Saklani A. Anti-inflammatory, cyclooxygenase(COX)-2, COX-1 inhibitory and antioxidant effects of Dysophylla stellata Benth. Fitoterapia. 2010;81(1):45-9. doi: 10.1016/j.fitote.2009.07.004. [PubMed:19632309]

20. Joseph S, Sabulal B, George V, Smina TP, Janardhanan KK. Antioxidative and antiinflammatory activities of the chloroform extract of Ganoderma lucidum found in South India. Sci Pharm. 2009;77:111-21.

21. Liu CJ, Lin JY. Anti-inflammatory effects of phenolic extracts from strawberry and mulberry fruits on cytokine secretion profiles using mouse primary splenocytes and peritoneal macrophages. Int Immunopharmacol. 2013;16(2):165-70. doi: 10.1016/j. intimp.2013.03.032. [PubMed: 23590821]

22. Suresh V, Sruthi V, Padmaja B, Asha VV. In vitro anti-inflammatory and anti-cancer activities of Cuscuta reflexa Roxb. J Ethnopharmacol. 2011;134(3):872-7. doi: 10.1016/j.jep.2011.01.043. [PubMed: 21295129]

23. Tsai YD, Hsu HF, Chen ZH, Wang YT, Huang SH, Chen HJ, et al. Antioxidant, anti-inflammatory, and anti-proliferative activities of extracts from different parts of farmed and wild Glossogyne tenuifolia. Ind Crops Prod. 2014;57:98-105. doi: 10.1016/j. indcrop.2014.03.033. 